\title{
Public Health Genomics
}

\section{Original Paper}

Public Health Genomics 2011;14:53-58

DOI: $10.1159 / 000321962$
Received: May 13, 2010

Accepted: October 12, 2010

Published online: November 13, 2010

\section{Health System Implications of Direct-to- Consumer Personal Genome Testing}

\author{
Amy L. McGuire ${ }^{a}$ Wylie Burke ${ }^{b}$ \\ ${ }^{a}$ Center for Medical Ethics and Health Policy, Baylor College of Medicine, Houston, Tex., and \\ ${ }^{b}$ Department of Bioethics and Humanities, University of Washington, Seattle, Wash., USA
}

\section{Key Words}

Consumer safety - DNA test kit · Personal genome testing, direct-to-consumer

\begin{abstract}
Direct-to-consumer personal genome testing is now widely available to consumers. Proponents argue that knowledge is power but critics worry about consumer safety and potential harms resulting from misinterpretation of test information. In this article, we consider the health system implications of direct-to-consumer personal genome testing, focusing on issues of accountability, both corporate and professional.
\end{abstract}

Copyright $\odot 2010$ S. Karger AG, Basel

\section{Introduction}

Genomics has become even more personal with the introduction of direct-to-consumer personal genome testing (DTC PGT). For just a few hundred dollars it is now possible to discover one's genetic predisposition to a variety of diseases, conditions, and traits without even having to go through a physician. Technologically, the retail DNA test kit represents a major advance. It was named 'Invention of the Year' by Time magazine in 2008 [1], and many people, including several renowned scientists and physicians, have called it 'revolutionary' [2].
Direct-to-consumer genomics certainly has the effect of speeding the translation of scientific discovery, but by divorcing itself from the traditional health care system, does something get lost in translation along the way? Advocates insist that knowledge is power but critics worry about consumer safety and the dangers of uninformed (or misinformed) decision making [3-7]. From a public policy perspective, questions remain regarding whether DTC PGT should be more tightly regulated and how it ought to be integrated into medical practice, if at all. In this article, we consider the health system implications of DTC PGT, focusing on issues of accountability, both corporate and professional.

\section{Nature of Test Results}

It is illegal in all US states to practice medicine without a medical license. The practice of medicine is defined by state law, and typically involves diagnosing a disease or condition, developing a treatment plan, and/or providing treatment for a medical condition or disorder [8]. Some personal genome test companies openly embrace a role as providers of information that is intended to inform health care. For example, the website for Navigenics, a major manufacturer of DTC PGT, states: 'Our goal is to empower you with genetic insights to help you improve your health through disease prevention, early detection, and

\section{KARGER}

Fax +41613061234

E-Mail karger@karger.ch

www.karger.com (c) 2010 S. Karger AG, Basel

Accessible online at: www.karger.com/phg
Amy L. McGuire, JD, PhD

Center for Medical Ethics and Health Policy

Baylor College of Medicine, One Baylor Plaza, MS 420

Houston, TX 77030 (USA)

Tel. +1 713798 2029, Fax +1 713798 5678, E-Mail amcguire@bcm.edu 
medication choices tailored to you' and the company employs a licensed health care provider to order tests and help communicate results [9]. However, other companies, such as 23 andMe, market their test 'for informational purposes only' and warn consumers that their services 'cannot be used for health ascertainment and disease purposes' [10].

DTC PGT companies provide 3 types of information: ancestry, recreational information about traits that do not necessarily impact health (e.g. genetic associations related to running speed, earwax, and bitter taste), and health-related information (e.g. about gene variants shown to be associated with increased risk of developing cancer, heart disease, or diabetes). The first 2 categories of information may not pertain directly to health, but the third clearly does, and because all of the results are communicated in 1 report it is not plausible to try to disentangle these multiple test purposes [11]. Therefore, as long as some results are health-related, providers of DTC PGT are engaged with the health care system.

Although the information provided by most tests within DTC PGT is not diagnostic of a specific disorder, they provide predictive information that might be used to make health care decisions. Reports from 2 well-known physician-scientists exemplify this use of risk information. Dr. Francis Collins, geneticist and director of the National Institutes of Health, has himself purchased DTC PGT and touts the health benefits he received from learning that he is at increased risk of developing diabetes, which led him to go on a diet and hire a personal trainer: 'As a physician, I had known for years about a long list of general recommendations for maintaining good health, but I hadn't necessarily followed them. Now, with these specific threats, I found I was more attentive ... Despite all of the limitations of the data, the disclosure of this personalized genetic information provided a motivator for specific actions' [2].

Dr. Mehmet Oz, a renowned cardiothoracic surgeon who frequently appears on the Oprah show, also purchased DTC PGT. While on the Oprah show Dr. Oz shared that his test results indicated a predisposition to developing macular degeneration, which can cause vision loss. 'Armed with this knowledge, Dr. Oz is taking preventive measures to preserve his vision and keep his eyes healthy' by eating more leafy green vegetables [12].

These examples suggest a potential for DTC PGT to motivate beneficial behavior change, although research has not yet substantiated significant effects [13]. Further study is needed, not only to determine whether behavioral effects occur, but also to ensure they are beneficial.
Instead of motivating a healthier lifestyle, positive results could lead to a fatalistic attitude, and negative test results could produce false reassurance. For example, Dr. Oz also discovered though DTC PGT that he is $30 \%$ less likely than the average man to develop prostate cancer. Based on this information Dr. Oz concluded that he can be 'a little less diligent' about scheduling regular prostate examinations. As he said on national television: 'Think of the trade-off. Thanks to this test, I don't have to have rectal exams' [12].

As these 2 examples illustrate, even well-informed consumers may consider the information provided to be sufficiently informative to guide medical decisions. The U S Government Accountability Office, in its investigation of DTC companies agreed, finding that despite company disclaimers, results contained health-related predictions (i.e. risk of developing medical conditions) that a consumer could interpret as diagnostic $[6,14]$. And in a 2008 survey of social networkers' views toward DTC PGT it was found that $60 \%$ of survey respondents who reported that they have used DTC PGT services $(n=63)$ and $38 \%$ of those who say they would use DTC PGT services $(n=693)$ consider the results to be equivalent to a medical diagnosis [15].

\section{Reliability of Test Results}

Given the evidence that at least some consumers are likely to make (potentially significant) health care decisions on the basis of information from DCT PGT, it is important that the information they are receiving is reliable and based on best available scientific evidence. However, observations from many sources suggest this is not always the case. In one study, researchers assessed the scientific evidence supporting claims about gene-disease associations for 56 genes included in genetic tests available via the internet and found insufficient evidence to judge the association in many cases [16]. Where evidence was available, the association was significant in fewer than $40 \%$ of cases, and where significant, the risk was often modest. In addition, current research findings account for only a small proportion of the genetic risk associated with most common diseases [17], and none of these tests account for family history, which in many cases is a more accurate guide to heritable risk then genetic testing, or for non-genetic risk factors such as weight or smoking history. It is therefore not surprising that the US Government Accountability Office recently found inconsistencies between the results of different DTC compa- 
nies and discrepancies between DTC test results and the consumer's actual health history [14]. For example, in 1 case, a consumer who had a pacemaker implanted 13 years prior to treat an irregular heartbeat was told that, based on his genetic test results, he was at decreased risk of developing such a condition [14]. Another consumer, who was a reporter, noted that his results from 2 different commercial DTC tests gave conflicting information: 1 company found him to be below average risk for macular degeneration and higher risk for coronary heart disease, while the other company predicted the opposite for both disorders [18].

An important contributor to these discrepancies is the modest risk identified by most DTC tests. In the reporter's example, one company found his risk for coronary artery disease to be $6 \%$ above average, while the other company found a risk $17.5 \%$ below average. In scientific terms, his relative risk ranged from 0.825 to 1.06 of average risk - in other words, his risk was close to average by either test. This range likely reflects the range of normal as measured by different markers or data derived from different populations. Certainly neither result suggests that he should pursue cardiac prevention any differently than most people.

\section{Public Policy Considerations}

\section{Corporate Responsibility}

Given the limited scientific base for many tests and the modest risk information associated with most results, it is reasonable to ask what kind of accountability testing companies should have. Arguably, consumer protection measures should address 3 areas: (1) the test should measure what it claims to measure, (2) the claims made for a test should be accurate, and (3) the test should be reasonably safe. The policy considerations differ for each area.

Ensuring that a test actually measures the property it claims to measure - in other words, that the test result has analytic validity - is the focus of governmental laboratory regulations under statutes such as the U.S. Clinical Laboratory Improvement Amendments (CLIA) [19]. This regulatory approach mandates standardization of both test procedures and the handling of samples on which testing is done. The information available about the analytic validity of DTC genomic tests, at least those from major laboratories, is reassuring.

However, assuring that a test result has analytic validity does not address difficulties in test interpretation. Claims that are not supported by scientific evidence are

Direct-to-Consumer Personal Genome Testing clearly a problem $[8,16]$. But even when a finding is supported by scientific evidence, the reporting may be misleading. Is it reasonable, for example, that a DTC test result indicating a relative risk of 1.06 be reported as demonstrating an increased risk for heart disease? To what extent should test developers be expected to provide caveats based on the small risks identified, the variation in risk seen in different studies, or the inherent limitations in risk prediction that stem from the small attributable fraction of risk for most gene variants? The policy concern here is truth in marketing, and policy approaches generally take the form of regulation of marketing claims, as in the requirements of the US Federal Trade Commission (FTC). The FTC has issued a consumer advisory about DTC genetic tests, warning that 'some of these tests lack scientific validity, and others provide medical results that are meaningful only in the context of a full medical evaluation' [7].

The agency invites consumers to file complaints concerning fraudulent, deceptive, and unfair business practices, but the limitations in current DTC tests and the ways in which they are marketed raise questions about the need for more aggressive consumer protection. In a study of web pages for major DTC companies, for example, Sterling et al. found evidence that manufacturer claims were not in compliance with FTC regulations concerning the content and placement of claims and qualifiers [20]. This finding suggests that more active surveillance of marketing may need to be considered.

The US Food and Drug Administration (FDA) recently sent letters to several companies involved in DTC testing, indicating its intent to regulate the industry [21]. Alberto Gutierrez, director of the FDA's office of in-vitro diagnostics, believes that FDA review and approval is legally required for DTC tests: 'They are making medical claims. We don't know whether the test works and whether patients are taking actions that could put them in jeopardy based on the test' [7].

The FDA has overlapping jurisdiction with both CLIA and the FTC to ensure analytic validity and to limit the marketing of tests with poor clinical validity. The FDA can also prevent a test from moving to market until there is sufficient evidence that it is safe and effective. Premarket scrutiny will be important for some high-risk tests, but we have argued that for most DTC tests, the risks and benefits of testing should be longitudinally assessed through enhanced post-market surveillance [22].

Even when DTC tests have adequate clinical validity, the claims for results are accurate, and the benefits of testing are well-established, there are potential concerns

Public Health Genomics 2011;14:53-58 
about consumer safety. These are most readily seen for the subset of DTC tests that provide information about high-risk variants. For example, some companies provide testing for mutations in the BRCA1 and BRCA2 genes, associated with lifetime risks for $50-85 \%$ for breast cancer and up to $60 \%$ for ovarian cancer. Some experts question whether it is appropriate for consumers to receive information of this kind on their own. Some companies provide telephone counseling by company-employed counselors [2], but this level of support may not be sufficient to prevent psychological harms or misinterpretation of test results. Although these concerns are most apparent for tests conferring high risk, tests conferring modest risks may also raise questions when they address certain health concerns: for example, some manufacturers offer tests that identify a propensity to addiction.

In addition to psychological harm and misunderstanding of test results, genetic tests conferring information about health risk have the potential to trigger additional testing and treatment. This response is appropriate for results like those from BRCA testing. However, if the risk involved is small, or uncertain, additional action is not necessarily beneficial and could cause harm [23].

Physician Involvement and Professional Responsibility

Concerns about safety may be mitigated by the appropriate involvement of health care professionals in the delivery and interpretation of DTC test results. Physician involvement may also be legally required, if the tests are deemed to constitute diagnostic information. And it is ethically recommended; the American College of Medical Genetics (ACMG), American Medical Association (AMA), and the FTC all call for a qualified health care provider to supervise genetic testing $[7,24,25]$. Therefore it is to be expected that consumers will bring their DTC results to their physicians for help interpreting them. Indeed, consumers are encouraged to do so. Some company websites explicitly advise cusstomers to contact their physician with concerns or questions [26]. The FTC advisory on genetic tests recommends: 'Ask your doctor or a genetic counselor to help you understand your test results' [7].

The survey of social networkers mentioned above confirmed that most $(78 \%)$ respondents who report that they would consider DTC testing $(n=693)$ would ask their physician for help interpreting their results and $61 \%$ of all respondents $(n=1,087)$ believe that physicians have a professional obligation to help interpret results [15].

However, DTC tests pose significant challenges for health care providers. Most of the tests provided through DTC PGT are not part of routine health care and do not have established clinical utility. This evidence gap is widely acknowledged, and a recent consensus among leaders in the field called for an ambitious research agenda to evaluate clinical value for the kinds of genetic risk information included in DTC tests [27]. As research is done it is likely that benefits will be proven for some tests and not others. For example, some pharmacogenomic tests provide specific, useful information about drug efficacy or risks of adverse events [28, 29], making this a promising area for development of genetic tests. Yet, when a CDC panel assessed a pharmacogenomic test marketed to guide psychiatric drug use, it found no evidence to support test use and identified some potential harms of testing, including the potential for less effective treatment [30]. The panel discouraged use of this test in the absence of clinical trials that provide evidence for benefit.

Primary care physicians are therefore faced with talking to patients about DTC genomic test results of dubious clinical value - tests that raise questions about risk but provide little or no helpful guidance for prevention or disease management. Many test results will be unfamiliar to the physician, and the ensuing discussions are likely to take time from other more useful health care - in essence, consuming the limited time physicians have with each patient [23]. The disruption imposed by these discussions might be mitigated by authoritative and readily accessible web resources to provide physicians and consumers with up-to-date information about the range of genetic risks tested for in DTC tests. However, the creation of such resources represents a different kind of resource demand: to be unbiased, they will likely require support from public or professional organizations. Is it appropriate for untested commercial products to make these kinds of claims on health care, public and professional resources?

\section{Health System Implications}

These considerations lend support to policy initiatives that would require pre-market evaluation, to assure that at least high-risk health-related DTC tests are valid and reliable [22]. DTC tests that provide results with well-established clinical implications (like those for mutations in the BRCA genes) should be incorporated into an individual's health care and might contribute to the improved health care that is currently claimed for DTC tests.

However, those tests that provide ambiguous or unproven risk information have the potential to impose unnecessary cost and time burdens on health care systems. In addition, responding to risk information that does not have well-established clinical implications may not al- 
ways be good for individuals. The controversy surrounding PSA testing for prostate cancer offers an example to illustrate that risk information poses risks as well as benefits [31]. The test is intended to identify early prostate cancer, in order to allow early and effective treatment. For some men - the minority destined to have progressive metastatic prostate cancer - this testing process appears beneficial. The experience with testing to date suggests, however, that most men found to have prostate cancer after PSA screening are unlikely to die of this condition; many might never have known they had cancer if unscreened and others would do as well if they were treated after they developed symptoms. Basing care on risk information in this case leads to over-diagnosis; in addition to inconvenience and expense, adverse effects of treatment can occur, including pain, incontinence and impotence.

Genomic DTC tests offer a potential for a similar kind of over-diagnosis. They will identify many relatively modest risks for common diseases like heart disease, diabetes, and cancer (including prostate cancer). Both physicians and consumers may find it difficult to ignore the risks, and as surveys and anecdotal reports suggest, may be tempted to over-estimate the genetic risk effect. The tests and treatments that result could lead to iatrogenic harm, because virtually all medical interventions have some potential for harm [32]. In other words, genomic tests of unproven clinical value raise the risk of a cascade effect [33], in which tests with uncertain implications lead to additional care, with its associated risks of harm.

This potential for harm underscores the importance of calls for rigorous research to define the benefits and harms of genomic risk information [27]. A fundamental policy concern, as important as those related to the quality of tests, is to determine the appropriate measures to evaluate the potential for clinical benefit from personal genomics. Several elements are likely to be needed, including adequate funding, the involvement of diverse disciplines, study designs that allow for a comparison of care based on genetic risk versus alternatives [34], and research infrastructures that allow tests to be evaluated in clinical settings [35].

As an initial step, more foundational work is needed to define the circumstances under which genetic risk information is likely to have clinical utility and generate robust hypotheses of benefit for specific tests. For example, it is difficult to imagine any clinical circumstance under which a test predicting a $6 \%$ increase in risk for a common complex disease would provide health care value. On the other hand, a genetic profile predicting a 3- to
4 -fold increased risk could conceivably inform preventive counseling or screening, particularly if data on modifiers of risk helped to identify potential interventions. In addition to directing future research, conceptual work of this kind could inform labeling standards for DTC tests.

As research infrastructures are developed, research should be directed toward tests providing sufficient predictive value and clinical opportunity to support a testable hypothesis of benefit. Studies should be designed to assess both the value of risk information for achieving improved health outcomes and the degree to which genetics provides added or unique benefits (or harms) compared to other risk assessment methods. This research agenda would not necessarily address DTC tests directly. However, well-designed research on PGT could help policy makers and clinicians to define those DTC tests that could legitimately inform health care. Further, DTC tests that do not meet the threshold of potential benefit required for research investment could be so labeled, assisting consumers and their health care providers to evaluate their significance.

\section{Acknowledgements}

Funded by the Greenwall Foundation Faculty Scholars Program in Bioethics, NIH R01HG004333 and NIH P50HG003374. Dr. McGuire serves on the scientific advisory board for Ion Torrent Systems. We thank Jill Oliver, MA, for valuable editorial assistance.

References

1 Hamilton A: Time's Best Inventions of 2008. Time Magazine, Oct 29, 2008. www.time. com/time/specials/packages/article/ 0,28804,1852747_1854493_1854113,00.html.

2 Collins F: The language of life: DNA and the revolution in personalized medicine New York, HarperCollins, 2010.

-3 Hogarth S, Javitt G, Melzer D: The current landscape for direct-to-consumer genetic testing: legal, ethical, and policy issues. Ann Rev Genomics Hum Genet 2008;9:161-182.

4 Hunter DJ, Khoury MJ, Drazen JM: Letting the genome out of the bottle: will we get our wish? N Engl J Med 2008;358:105-107.

5 Federal Trade Commission: At-home genetic tests: a healthy dose of skepticism may be the best prescription. 2006. www.ftc.gov/ bcp/edu/pubs/consumer/health/hea02.shtm (accessed October 15, 2010).

6 Kutz G: Nutrigenetic testing: tests purchased from four web sites mislead consumers. Report No: GAO-06-977T. Washington, US Government Accountability Office, 2006, p 27. 
7 Stein R: Fears surround over-the-counter genetic tests. The Washington Post, May 11, 2010. www.msnbc.msn.com/id/37076766/ ns/health-more_health_news (accessed October 15, 2010).

8 Marietta C, McGuire AL: Currents in contemporary ethics. Direct-to-consumer genetic testing: is it the practice of medicine? J Law Med Ethics 2009;37:369-364.

9 www.navienics.com

10 23andMe: Terms of service. 2007. www. 23andme.com/about/tos (accessed October 15, 2010).

-11 Prainsack B, Reardon J, Hindmarsh R, Gottweis $H$, Naue U, Lunshof J. Personalized genomes: misdirected precaution. Nature 2008;465:34-35.

12 The Oprah Winfrey Show: Headline-making news. Oprah.com, November 14, 2008. www.oprah.com/oprahshow/Live-withRob-Lowe-Melissa-Etheridge-andMore/9\#slide (accessed October 15, 2010).

13 McBride CM, Bowen D, Brody LC, Condit CM, Croyle RT, Gwinn M, Khoury MJ, Koehly LM, Korf BR, Marteau TM, McLeroy K, Patrick K, Valente TW: Future health applications of genomics: priorities for communication, behavioral, and social sciences research. Am J Prev Med 2010;38:556-565.

14 Kutz G: Direct-to-consumer genetic tests: misleading test results are further complicated by deceptive marketing and other questionable practices. Report No: GAO-10847T. Washington, US Government Accountability Office, 2010, p 33.

15 McGuire AL, Diaz CM, Wang T, Hilsenbeck SG: Social networkers' attitudes toward direct-to-consumer personal genome testing. Am J Bioeth 2009;9:3-10.

16 Janssens AC, Gwinn M, Bradley LA, Oostra BA, van Duijn CM, Khoury MJ: A critical appraisal of the scientific basis of commercial genomic profiles used to assess health risks and personalize health inventions. Am J Hum Genet 2008;82:593-599.
17 Manolio TA, Collins FS, Cox NJ, Goldstein DB, Hindorff LA, Hunter DJ, et al.: Finding the missing heritability of complex diseases. Nature 2009;461:747-753.

18 Fleming N: Rival genetic tests leave buyers confused. The Sunday Times, September 2, 2008. www.timesonline.co.uk/tol/news/uk/ science/article4692891.ece (accessed October 15, 2010).

19 US Department of Health and Human Services, Centers for Medicare and Medicaid Services: Regulations and guidance: clinical laboratory improvement amendments. 2010. www.cms.gov/CLIA/09_CLIA_Regulations_and_Federal_Register_Documents. asp (accessed October 15, 2010).

20 Sterling R, Adams S, McLeod H, Evans JP Assessing claims, disclaimers, and performance of personal genomic services; in Caulfield T, Knoppers BM (co-chairs): Proceedings of The Age of Personalized Genomics: 5th International DNA Sampling Conference. Banff, 2010, p 106.

21 US Food and Drug Administration: Letters to industry. www.fda.gov/MedicalDevices/ ResourcesforYou/Industry/ucm111104.htm

22 McGuire AL, Evans BJ, Caulfield T, Burke W: Regulating direct-to-consumer personal genome testing. Science 2010; in press.

23 McGuire AL, Burke W: An unwelcome side effect of direct-to-consumer personal genome testing: raiding the medical commons. JAMA 2008;300:2669-2671.

24 American College of Medical Genetics: Statement on direct-to-consumer genetic testing. 2007. www.acmg.net/AM/Template. $\mathrm{cfm}$ ?Section $=$ Search $2 \&$ section $=$ Home Page_News_Releases\&template $=/ \mathrm{CM} / \mathrm{Con}-$ tentDisplay.cfm\&ContentFileID $=144 \quad$ (accessed October 15, 2010).

25 American Medical Association: Direct-toconsumer genetic testing. www.ama-assn. org/ama1/pub/upload/mm/464/dtc-genetictest.pdf (accessed October 15, 2010).

26 23andMe: Consent document. 2007. www. 23andme.com/about/consent (accessed October 15,2010$)$.
27 Khoury MJ, McBride CM, Schully SD, Ioannidis JP, Feero WG, Janssens AC, et al: The scientific foundation for personal genomics: recommendations from a National Institutes of Health-Centers for Disease Control and Prevention Multidisciplinary Workshop. Genet Med 2009;11:559-567.

28 Lai-Goldman M, Faruki H: Abacavir hypersensitivity: a model system for pharmacogenetic test adoption. Genet Med 2008; 10(12):874-878.

29 Longo R, D'Andrea M, Sarmiento R, Gasparini G: Pharmacogenetics in breast cancer: focus on hormone therapy, taxanes, trastuzumab and bevacizumab. Expert Opin Investig Drugs 2010, 19(suppl 1):S41-S50.

30 Evaluation of Genomic Applications in Practice and Prevention (EGAPP) Working Group: Recommendation from the EGAPP Working Group: testing for cytochrome P450 polymorphisms in adults with nonpsychotic depression treated with selective serotonin reuptake inhibitors. Genet Med 2007; 9:819-825.

31 Adami HO: The prostate cancer pseudoepidemic. Acta Oncol 2010;49:298-304.

32 Farley TA: Reforming health care or reforming health? Am J Public Health 2009;99:588590

33 Deyo RA: Cascade effects of medical technology. Annu Rev Public Health 2002;23: 23-44.

-34 Khoury MJ, Rich EC, Randhawa G, Teutsch SM, Niederhuber J: Comparative effectiveness research and genomic medicine: an evolving partnership for 21st century medicine. Genet Med 2009;11:707-711.

35 Institute of Medicine (US) Roundtable on Translating Genomic-Based Research for Health: Systems for research and evaluation for translating genome-based discoveries for health. Workshop summary. Washington, National Academic Press, 2009 